\title{
Avaliação da erosão hidrica pela alteração na superfície do solo em diferentes coberturas vegetais de uma sub-bacia hidrográfica no Município de Alegre, ES
}

\author{
Evaluationof water erosionchanges insurfacesoilin \\ different plant cover of Awatershedin Alegre, ES
}

\author{
Huezer Viganô Sperandio ${ }^{1 *}$; Roberto Avelino Cecílioº; Wesley Augusto \\ Campanharo $^{1}$; Cássio Fanchiotti Del Caro ${ }^{3}$; Maycon Patrício de Hollanda ${ }^{4}$
}

\section{Resumo}

A erosão é o processo de desprendimento, arraste e deposição de partículas de solo, que ocasiona a perda da capacidade produtiva dos solos, o assoreamento, além da eutrofização e a perda da qualidade das águas superficiais. Manter este processo de degradação em níveis toleráveis é uma das grandes preocupações ambientais. Com este trabalho objetivou-se avaliar as perdas de solo numa pastagem e numa regeneração florestal, através de um método simples temporal e economicamente - Método dos Pinos. O estudo foi composto por duas parcelas experimentais instaladas na sub-bacia do Rio Jacaré, Alegre - ES, com $108 \mathrm{~m}^{2}$ cada, sob diferentes coberturas vegetais, pastagem e regeneração florestal natural. Pela metodologia da alteração da superfície dos solos, cravou-se 40 estacas no solo, onde se procedia à leitura mensal. Foi verificada uma perda média de 6,08 Mg.ha ${ }^{-1}$ mês ${ }^{-1}$ e 3,34 Mg.ha ${ }^{-1}$ mês ${ }^{-1}$ de solo, na pastagem e regeneração, respectivamente. A média da leitura das estacas na pastagem foi $51,85 \%$ maior que na regeneração.

Palavras-chave: Método dos pinos, perdas de solo, pastagem, regeneração florestal

\begin{abstract}
Erosion is the process of detachment, drag and deposition of soil particles, which caused the loss of productive capacity of soils, siltation, and eutrophication and the loss of quality of surface waters. Keep this degradation process at tolerable levels is a major environmental concerns with this work aimed to evaluate the losses of soil in a pasture and forest regeneration through a simple temporal and economically - Pin Method. The study consisted of two experimental plots located in the watershed of the Rio Jacaré, Alegre - ES, with 108 square meters each, under different cover crops, pasture and natural forest regeneration. Methodology by changing the surface of the soil, dug up 40 stakes in the ground, where he proceeded to read monthly. It was observed an average loss of $6.08 \mathrm{Mg} \mathrm{ha}^{-1} \mathrm{month}^{-1}$ and $3.34 \mathrm{Mg} \mathrm{ha}^{-1}$ month $^{-1}$ soil, pasture and regeneration, respectively. The average reading of the stakes in the pasture was $51,85 \%$ higher than in regeneration.
\end{abstract}

Key words: Water erosion, method pin, losses of soil, grassland, forest regeneration

${ }^{1}$ Eng $^{\text {o }}$ Florestal. Mestrando do Programa de Pós Graduação em Ciências Florestais da Universidade Federal do Espírito Santo. E-mail: huezer@gmail.com; wesley-ac@hotmail.com

${ }^{2}$ Prof. Adjunto do Dept ${ }^{\circ}$ de Ciências Florestais e da Madeira da Universidade Federal do Espírito Santo. Bolsista Produtividade em Pesquisa do CNPq. E-mail: roberto.cecilio@ufes.br

${ }^{3}$ Eng $^{\circ}$ Florestal. Analista em Desenvolvimento Agropecuário do Instituto de Defesa Agropecuária e Florestal do Estado do Espírito Santo. E-mail: cassiofdc@hotmail.com

${ }^{4}$ Eng $^{\circ}$ Agr $^{\circ}$, Mestrando do Programa de Pós Graduação em Produção Vegetal da Universidade Federal do Espírito Santo. E-mail: mphollanda@hotmail.com

* Autor para correspondência 
O solo, em conjunto com a água, consiste nos recursos naturais mais disponíveis e utilizados na Terra, sendo essenciais na maioria das atividades humanas, especialmente na produção de alimentos. Em despeito da importância do recurso solo, contudo não se observa a adoção de um manejo conservacionista, visando preservar este bem público, que sofre constantemente processos de degradação ambiental devido à sua utilização predatória.

Um dos processos de degradação do solo mais atuantes é a erosão ocasionada pela ação das águas. Segundo Pruski (2006) o principio da erosão se dá na incidência das precipitações sobre o terreno, em que parte é interceptada pela vegetação, enquanto o restante atinge a superfície do solo, umedecendo os agregados do solo e reduzindo suas forças de coesão. Com a continuidade das chuvas ocorre à desintegração dos agregados em partículas menores, obstruindo os poros do solo, consequentemente provocando o selamento superficial. Além disso, o impacto da gota de chuva proporciona compactação, que associada ao selamento, reduz a taxa de infiltração da água. Quando a intensidade da chuva passa a ser maior do que a taxa de infiltração, iniciase o transporte das partículas desagregadas do solo pelo escoamento superficial.

Nos locais sob a ação de processo erosivo, além da remoção do solo em si, verificam-se a perda da capacidade produtiva, devido à remoção dos horizontes superficiais mais férteis, a deformação dos habitats da microfauna edáfica e o transporte de sedimentos e nutrientes pelo escoamento superficial, sendo depositados na rede de drenagem da bacia hidrográfica, e verificando ainda, um efeito negativo à paisagem local. Consequentemente à deposição no leito de drenagem ocorre o assoreamento e a eutrofização dos rios e lagos, com a perda da qualidade das águas.

Segundo o United Nations Environmental Program (1991), grandes áreas cultivadas podem se tornar improdutivas, ou pelo menos economicamente inviáveis, se a erosão hídrica não se mantiver em níveis toleráveis. Estudos indicam que a produtividade agrícola em 20 milhões de hectares é reduzida, a cada ano, a zero ou pelo menos tem a sua exploração agrícola tornada economicamente inviável devido à erosão e a degradação induzida pela mesma. Por erosão, no Brasil, são perdidos 600 milhões de toneladas de solo agrícola a cada ano (BAHIA; CURI; CARMO, 1992), associados a uma perda econômica na ordem de 4 bilhões de dólares em nutrientes, segundo Amorim (2003).

A intensidade dos processos erosivos é condicionada pele quantidade, intensidade e duração da precipitação, declividade, tipo de solo e de cobertura vegetal (DOMINGOS, 2006).

Compreender os fatores que integram o processo de erosão e quantificar as perdas de solo são atividades de grande importância, pois servem como base na elaboração de medidas que visem maximizar o uso dos recursos hídricos disponíveis e evitar os efeitos negativos decorrentes da produção, transporte e deposição de sedimentos (PAIVA, 2001).

Alguns autores como Bono (1994) e Cardoso (2003) citam o método da alteração na superfície do solo - Método dos pinos - como uma metodologia adaptada para avaliar perdas de solo em sistemas de culturas perenes e florestais, sendo um método prático e de baixo custo, em relação ao método da parcela-padrão. Cardoso (2003) insere a metodologia como de significativa relevância à um planejamento conservacionista, devido a acessibilidade temporal e econômica do método.

Do exposto, o objetivo deste trabalho foi quantificar e avaliar as perdas de solo ocasionada pelo escoamento superficial numa sub-bacia hidrográfica sob diferentes coberturas vegetais pelo método da alteração da superfície do solo (Método dos Pinos).

Os dados foram coletados na sub-bacia do Rio Jacaré, locada na Área Experimental e de Produção de Rive (AEPR), unidade pertencente ao Centro de 
Ciências Agrárias (CCA) da Universidade Federal do Espírito Santo (UFES), no município de Alegre ES. O clima da região enquadra no tipo CWa (Clima de inverno seco e verão chuvoso), de acordo com a classificação de Köppen.

Os dados mensais de precipitação foram coletados pela estação meteorológica automática pertencente ao Instituto Nacional de Meteorologia, localizada na AEPR/CCA, disponibilizados pelo Centro Universitário Norte do Espírito Santo.

$\mathrm{O}$ experimento constituiu-se na medição das perdas de solo em duas parcelas experimentais retangulares com dimensão de $108 \mathrm{~m}^{2}$ (6 metros em nível e 18 metros no sentido do declive), sob duas diferentes coberturas vegetais: Pastagem (PA) ocupada por capim gordura (Melinis minutiflora) com pastoreio bovino no sistema extensivo, com roçadaspara manejo de arbustos e plantas espontâneas, solo com textura média e granulometria de $68,27 \%$ de areia, 4,04\% de silte e $27,69 \%$ de argila, com densidade de $1,19 \mathrm{~kg} \mathrm{~cm}^{-}$ 3;e Regeneração Natural (RN) caracterizada como Floresta Estacional Semidecidual em estado de regeneração em nível primário, com baixo índice de diversidade e espécies de baixo porte, solo com textura média e granulometria de $64,61 \%$ de areia, $5,7 \%$ de silte e $29,69 \%$ de argila, com densidade de $1,21 \mathrm{~kg} \mathrm{~cm}^{-3}$. Ambas apresentando declividade média de $54 \%$ e altitude média de $167 \mathrm{~m}$, e solo caracterizado como Latossolo Vermelho-Amarelo (LVA).

A avaliação das perdas de solo por escoamento superficial (erosão hídrica) foi realizada pelo método da mudança na superfície do solo, por meio de marcos superficiais (estacas de madeira com 0,2 $\mathrm{m}$ de comprimento e seção transversal de $0,05 \mathrm{~m}$ ), adaptando a metodologia proposta por Bertoni e Lombardi Neto (1993). Onde em cada parcela, foi cravado 40 marcos estando dispostos numa malha retangular, de $2 \mathrm{~m} \times 2 \mathrm{~m}$, onde foram cravados até uma marca de $0,15 \mathrm{~m}$, ficando expostos $0,05 \mathrm{~m}$ da mesma. As parcelas foram instaladas na região mediana da encosta, com comprimento de rampa da encosta de $120 \mathrm{~m}$.

As leituras nas estacas foram mensais, de dezembro de 2008 a novembro de 2009, sendo realizadas diretamente na estaca, onde se procedia a mensuração pela haste de um paquímetro, com aproximação de 0,001 m, conforme Cardoso (2003).

O volume de solo mensal erodido nas parcelas experimentais foi determinado a partir do produto do volume pela densidade do solo, matematicamente observado na Equação 1, apresentando modificações quanto à metodologia utilizada por Bono (1994) e Cardoso (2003).

$$
P=\Delta h^{*} A * D s
$$

em que: $\mathrm{P}=$ perda de solo $\left(\mathrm{Mg} \mathrm{ha}^{-1}\right) ; \Delta \mathrm{h}=$ desvio da altura dos pinos por parcela em relação à superfície original $(\mathrm{m}) ; \mathrm{A}=$ área $\left(10000 \mathrm{~m}^{2}\right)$; Ds = densidade do solo $\left(\mathrm{kg} \mathrm{cm}^{-3}\right)$

Por meio de programa específico, tendo por base a distribuição dos pinos no interior das parcelas e as leituras mensais dos marcos superficiais, confeccionou-se o modelo de mudança na superfície do solo ocasionada pelo escoamento superficial no período em estudo, utilizando-se do interpolador krigagem.

A Tabela 1 apresenta os valores mensais das perdas de solo estimado pela alteração na superfície do solo bem como a precipitação média mensal. Nota-se uma significativa variação temporal das perdas de solo nas parcelas, conseqüência dos processos erosivos e seus agentes (precipitação, declividade e cobertura vegetal).

Na pastagem ocorreram as maiores perdas de solo, variando de 2,03 $\mathrm{Mg} \mathrm{ha}^{-1} \mathrm{ano}^{-1} \mathrm{em}$ novembro/2009 a $17,05 \mathrm{Mg} \mathrm{ha}^{-1} \mathrm{ano}^{-1} \mathrm{em}$ julho/2009, apresentando uma perda média mensal de aproximadamente $6,08 \mathrm{Mg} \mathrm{ha}^{-1}$ ano $^{-1}$ de solo, num total de $72,99 \mathrm{Mg}$ ha $^{-1}$ ano ${ }^{-1}$ durante o período estudado. Esta perda 
é decorrente da elevada declividade da parcela e da baixa cobertura vegetal existente. Indicando o inadequado manejo sofrido pelo local em estudo, característica largamente visível nas pastagens capixabas. Ressalta-se ainda, que o solo apresentase muito arenoso e que houve existência de pastoreio no interior da parcela experimental.

Tabela 1. Valores mensais de perda de solo determinadas pelo método da alteração na superfície.

\begin{tabular}{cccc}
\hline Mês & \multicolumn{2}{c}{$\begin{array}{c}\text { Perdas de Solo }\left(\mathbf{M g ~ h a}^{-1}\right) \\
\text { Regeneração }^{\text {Pastagem }}\end{array}$} & $\begin{array}{c}\text { Precipitação } \\
(\mathbf{m m})\end{array}$ \\
\hline dez/08 & 6.43 & 3.27 & 250.40 \\
jan/09 & 3.22 & 1.96 & 124.20 \\
fev/09 & 15.44 & 7.19 & 138.00 \\
mar/09 & 3.22 & 4.58 & 101.30 \\
abr/09 & 5.79 & -1.31 & 53.20 \\
mai/09 & 7.08 & 13.74 & 23.70 \\
jun/09 & 17.05 & 3.60 & 25.20 \\
jul/09 & 2.57 & 1.64 & 28.50 \\
ago/09 & 3.54 & 1.96 & 51.10 \\
set/09 & 3.86 & 1.31 & 102.60 \\
out/09 & 2.77 & 1.05 & 199.50 \\
nov/09 & 2.03 & 0.98 & 215.20 \\
\hline Total & 72.99 & 39.97 & 1312.90 \\
\hline Média & 6.08 & 3.33 & \\
\hline CV $(\%)$ & 1.21 & 0.85 & \\
\hline DP & 5.01 & 3.91 & \\
\hline
\end{tabular}

Fonte: Elaboração dos autores.

O resultado encontrado corrobora com Santos et al. (1998) que, trabalhando com o método da alteração na superfície do solo, sob chuva natural, em diferentes sistemas de preparo do solo e gramíneas, entre o período de dezembro de 1991 a dezembro de 1993, encontraram valores de perdas de solo em torno de 3,4 a 151,2 $\mathrm{Mg} \mathrm{ha}^{-1} \mathrm{ano}^{-1}$. Silva et al. (2005), analisando perdas anuais de solo em parcelas desnudas encontrou valores de 205,65 e $14,90 \mathrm{Mg} \mathrm{ha}^{-1}$ em média para o Cambissolo e Latossolo, respectivamente.

As menores perdas são observadas para o sistema sob regeneração, resultado da interceptação das gotas de chuvas pelo dossel da regeneração, existência de uma considerável camada de folhas (serapilheira), apresentando significativa quantidade de matéria orgânica, o que condiciona agregados de maior estabilidade e, por consequência, melhor estruturação e maior permeabilidade (MARTINS et al., 2003), contudo as perdas de solo ainda são consideradas altas, se comparadas à literatura como Martins et al. (2003), que encontrou 0,13 $\mathrm{Mg} \mathrm{ha}^{-1}$ ano $^{-1}$ para floresta nativa, no município de Aracruz - ES, mas a parcela apresenta-se em estado secundário de regeneração florestal, com características ainda da cultura anteriormente instalada (pastagem), com isso, as perdas no desenvolver da sucessão ecológica tendem a reduzir, além disso, apresenta uma elevada declividade. Pois quanto maior a declividade, mais elevada são as perdas de solo no local, porque quanto maior a 
declividade maior será a velocidade com que a água irá escoar, consequentemente, maior será o volume carreado devido a força erosiva (MENDES, 2006).

As perdas na regeneração em estado inicial encontra-se equiparada com culturas anuais, como o consórcio de milho, feijão e algodão, estudado por Silva et al. (1989), que verificou perdas de solo em torno de 41,4 $\mathrm{Mg} \mathrm{ha}^{-1} \mathrm{ano}^{-1}$. Corroborando ainda, com Pessoa (2007) que estimou perdas de 141,85 $\mathrm{Mg}$ ha $^{-1}$ ano $^{-1} \mathrm{em}$ Neossolo Litólico sob vegetação natural de Cerrado em Serra Talhada PE, avaliando ainda, que os processos erosivos, determinou a significância do banco de sementes presentes na área, fator fundamental aos processos de regeneração florestal, como a parcela de estudo.

Nota-se ainda no mês de maio, que há deposição de solo na parcela sob regeneração, oriundo da quase inexpressiva precipitação ocorrida no local, fato que não proporcionou a quantidade necessária de água para ocorrência do escoamento superficial em toda a parcela, o que impossibilitou o arraste das partículas do solo, fazendo com que as mesmas se depositassem nos locais com menor declividade e/ou presença superficial de raízes, troncos e serapilheira, contudo neste mesmo período a pastagem sofreu incremento positivo na taxa de perda de solo, possivelmente ocasionado pelo manejo adotado (roçada e retirada de plantas espontâneas).

Verifica-se que os volumes mensais da pastagem tendem a ser o dobro da regeneração, focando a importância dos sistemas florestais nas medidas preventivas da erosão.

Pela Figura 1, observa-se a alteração sofrida pela superfície do solo em decorrência dos processos erosivos no período em estudo (Dezembro/2008 a Novembro de 2009). Nota-se uma tendência no maior arraste de solo na pastagem, em relação à regeneração, com expressiva variabilidade dentro das parcelas. Esta variabilidade de ocorrência do arraste e deposição de solo no espaço e no tempo estão relacionados com os processos inerentes da erosão hídrica, que se iniciam com a incidência das precipitações e o desenvolvimento de toda a cadeia do processo erosivo (desintegração dos agregados, obstrução dos poros do solo, empoçamento da água, escoamento superficial e transporte dos sedimentos) e com o manejo da cobertura vegetal. Na pastagem, esta grande variabilidade espacial interna esta vinculada à interferência antrópica e animal na área, que apresenta um intenso micro relevo ocasionado pelas "trilhas dos bovinos". Essas trilhas tendem a direcionar e aumentar a intensidade do escoamento superficial, devido à inexistência de cobertura vegetal e à maior compactação existente pelo caminhar dos animais. A ação antrópica baseiase no manejo da pastagem, com roçadas, retirada de plantas invasoras e a condução do sistema de pastoreio no local.

Os valores dos desvios na alteração da superfície do solo foram mais significativos na Pastagem, que apresentou valor médio de alteração de $0,0054 \mathrm{~m}$, enquanto na Regeneração este valor foi de $0,0028 \mathrm{~m}$, superando aqueles obtidos por Cardoso (2003) que determinou uma alteração média variando entre 0 a $0,008 \mathrm{~m}$ em floresta nativa.

É ressalvado que os resultados podem estar relacionados com o tempo necessário para adequação da superfície do solo, pela inserção das estacas nas parcelas, o que provocou interferência na continuidade superficial do terreno.

Um bom planejamento na instalação da pastagem e na condução (manejo) da mesma tende a reduzir essas perdas de solo, pelo aumento da cobertura vegetal, minimizando assim o impacto das gotas de chuva e gerando barreiras ao escoamento superficial, levando-a aos limites toleráveis.

Do exposto pode-se afirmar para a área em estudo que a parcela sob Pastagem apresentou maior perda de solo no período estudado, sendo cerca de 55\% superior à parcela sob Regeneração Florestal Natural no que se tange o volume de solo erodido, além de maior variabilidade interna. Porém em relação à alteração na superfície do solo a Regeneração Florestal Natural foi 51,85\% inferior à Pastagem. 
Figura 1. Alteração na superfície do solo decorrente do escoamento superficial, sendo (h) leitura no marco superficial, (L) largura da parcela e (C) comprimento da parcela.

Pastagem

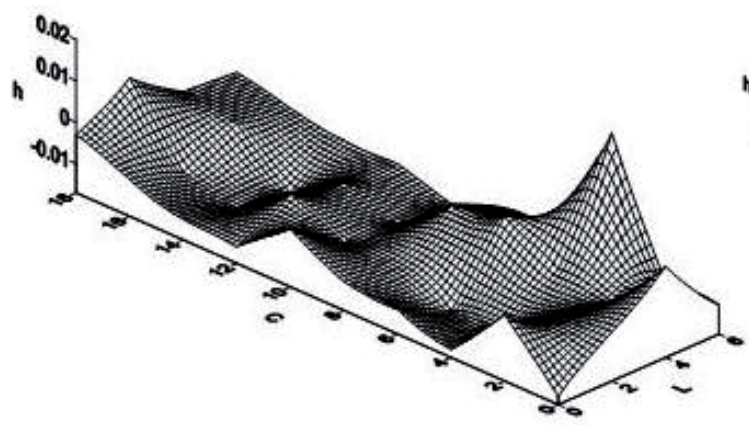

Fonte: Elaboração dos autores.

Ressalta-se ainda a importância de se desenvolver metodologias quanto a avaliação qualitativa da erosão verificada pelo método dos pinos, visto que a metodologia tende a ser muito utilizada em projetos à campo, por ser largamente acessível economicamente, contudo, superestimando as perdas de solo se avaliada por padrões existentes.

\section{Referências}

AMORIM, R. S. S. Avaliação dos modelos de predição da erosão hídrica USLE, RUSLE e WEPP para condições edafoclimáticas brasileiras. 2003. Tese (Doutorado em Engenharia Agrícola) - Universidade Federal de Viçosa, Viçosa, MG.

BAHIA, V. G.; CURI, N.; CARMO, D. N. Fundamentos de erosão do solo (tipos, formas, mecanismos, fatores determinantes e controle). Informe Agropecuário, Belo Horizonte, v. 176, n. 16, p.25-31, 1992.

BERTONI, J.; LOMBARDI NETO, F. Conservação do solo. São Paulo: Ícone, 1993. 355 p.

BONO, J. A. M. Sistemas de melhoramento de pastagens nativas visando ao aumento de produtividade $e$ conservação do solo. 1994. Dissertação (Mestrado em Solos e Nutrição de Plantas) - Universidade Federal de Lavras, Lavras, MG.

CARDOSO, D. P. Avaliação da erosão pela mudança na superficie do solo em sistemas florestais. 2003. Dissertação (Mestrado em Ciência do Solo) - Universidade Federal de Lavras, Lavras, MG.
DOMINGOS, J. L. Estimativa de perda de solo por erosão hídrica em uma Bacia Hidrográfica. 2006. Tese (Doutorado em Geografia) - Universidade Federal do Espírito Santo, Vitória.

MARTINS, S. G.; SILVA, M. L. N.; CURI, N.; FERREIRA, M. M.; FONSECA, S.; MARQUES, J. J. G. S. M. Perdas de solo e água por erosão hídrica em sistemas florestais na região de Aracruz (ES). Revista Brasileira de Ciência do Solo, Viçosa, MG, v. 27, n. 3, p. 395-403, 2003.

MENDES, C. A. R. Erosão superficial em encosta ingreme sob cultivo perene e com pousio no município de Bom Jardim - RJ. 2006. Tese (Doutorado em Engenharia de Civil) - Universidade Federal do Rio de Janeiro, Rio de Janeiro.

PAIVA, E. M. C. Evolução de processo erosivo acelerado em trecho do Arroio Vacacai Mirim. Revista Brasileira de Recursos Hídricos, Porto Alegre, v. 6, n. 2, p. 129135, 2001.

PESSOA, L. M. Variação espacial e sazonal do banco de sementes do solo em uma área de Caatinga, Serra Talhada, PE. 2007. Dissertação (Mestrado em Botânica) - Universidade Federal Rural de Pernambuco, Recife, PE.

PRUSKI, F. F. Processo físico de ocorrência da erosão hídrica. In: (Org.). Conservação de solo e água: práticas mecânicas para o controle da erosão hídrica. Viçosa, MG: UFV, 2006. v. 1, p. 25-40. 
SANTOS, D.; CURI, N.; FERREIRA, M. M.; SILVA, I. F.; CAMPOS FILHO, O. R.; ANDRADE, A. EVAngElista, A. R.; CRUZ FILHO, A. B.; P.; COÊLHO, E. A. C.; DINIZ, E. J. Influência do cultivo TEXEIRA, W. G. Perdas de solo e produtividade de isolado e do consórcio sobre as perdas de solo e água pastagens nativas melhoradas sob diferentes práticas de manejo. Pesquisa Agropecuária Brasileira, Brasília, v. 33, n. 2, p. 183-189, 1998.

numa Terra Roxa Estruturada. Revista Brasileira de Ciência do Solo, Campinas, v. 13, n. 1, p. 111-115, jan./ abr. 1989.

SILVA, A. M.; SILVA, M. L. N.; CURI, N.; LIMA, J. M.; AVANZI, J. C.; MARTINS, M. M. Perdas de solo, água, nutrientes e carbono orgânico em Cambissolo e Latossolo sob chuva natural. Pesquisa Agropecuária Brasileira, Brasília, v. 40, n. 12, p. 1223-1230, 2005.

UNITED NATIONS ENVIRONMENTAL PROGRAM. Status of desertification and implementation of the UM plano f action to combat desertification. Nairóbi, Kenya: UNEP, 1991. 
